\title{
APRENDER A VIVIR MESTIZAMENTE
}

\author{
Demetrio Velasco
}

\begin{abstract}
Resumen: A propósito del título. I. La paradójica persistencia de «la obsesión del mestizaje». La vigencia del color de la piel y de la racialización de las relaciones humanas. Tocqueville y los prejuicios del amo, de la raza y del blanco. II. Aprender a pensar (imaginar)la realidad mestizamente. La necesidad «nómica» de los seres humanos y las «reglas de pureza» como constantes antropológicas. La obsesión patológica por las reglas de la pureza y la obsesión identitaria con sus correlativas políticas identitarias. El pluralismo, la multiculturalidad y sus límites, como marco de una adecuada afirmación del mestizaje. III. La deconstrucción de los imaginarios mixtofóbicos y racistas y de las políticas identitarias. «Somos mestizos y los mestizos no nos podemos dividir». El proceso de globalización y nuestra identidad topopoligámica y fronteriza. El prejuicio de la Metafísica del Uno. Las trampas del singular y los peligros del jacobinismo. Las confusiones acerca de la relevancia moral de la diversidad cultural. IV. Deconstruyendo las narcisistas secuencias lógicas que recorren las identidades polémicas y excluyentes y las políticas identitarias, legitimadoras de la desigualdad y de la dominación: fundamentalismos y nacionalismos excluyentes. V. Educar(se) en la convivencia mestiza. Igualdad y diferencia. El valor de la diferencia asociado a poder ejercer el derecho a la indiferencia. Aprender a vivir laicamente; actualizar las virtualidades de nuestra condición topopoligámica, fronteriza. Hacia una ciudadanía cosmopolita.
\end{abstract}

Quiero comenzar haciendo una advertencia que, aunque pueda parecer una obviedad, me parece de gran trascendencia para el tema que nos ocupa. El adverbio modal «mestizamente» tiene un sentido metafórico que, como decía Hobbes, suele estar en la raíz de uno de los diversos abusos del lenguaje, que impide a los individuos entenderse adecuadamente, ya que con él se puede hacer creer al otro algo que no queremos decir. ${ }^{1}$ De hecho, no faltan autores para quienes ha-

\footnotetext{
1 HobBes. «El segundo abuso, cuando se usan palabras metafóricamente, es decir, en un sentido diferente de aquel al que están ordenadas, engañando así a los otros.» El Leviatán (1989), Alianza editorial, p. 35.
} 
blar de «mestizaje» evoca algo indeseado que no está en mi intención sostener. ${ }^{2}$

El lector se preguntará por qué, siendo consciente de esta dificultad, he mantenido el concepto. La razón está en que, habiendo ya escrito sobre el término «mestizaje», en la obra titulada Glosario para una sociedad intercultural, ${ }^{3}$ me he reafirmado en la convicción de que dicho término conlleva unas virtualidades que espero poder resaltar y que en nuestros días es importante subrayar.

Como acabo de mencionar, ya he escrito sobre esta cuestión algo de lo que para mí tiene de más significativo el fenómeno del mestizaje, y no pretendo repetir lo ya dicho. Quisiera abundar en algunas de las cuestiones ya planteadas y abordar otras nuevas.

\section{La paradójica persistencia de una obsesión}

El mismo día en que comencé a pensar en redactar estas páginas, el diario El País ofrecía un reportaje cuyo título decía así. «Millones de africanas se blanquean con cremas abrasivas. Ellos las prefieren blancas». «Blanquearse, desteñirse, es la obsesión que persigue a millones de africanas que diariamente se untan productos abrasivos en la piel para ser un poco menos negras, para subir en el escalafón social y lograr el objetivo final: volverse más deseables y gustar y gustarse más. En la carrera hacia el triunfo social pierden la melanina y contraen enfermedades cutáneas que van desde quemaduras, estrías, acné, alergias, hasta el cáncer de piel. Un fenómeno que recorre gran parte de Africa y

2 Véase M. ZÚÑIGA y J. Ansión. «¿Qué entender por interculturalidad?», en ZÚÑIGA Castillo, M/Ansión, J. Interculturalidad y Educación en el Perú (1997), Foro educativo. Lima, pp. 9-20. Se preguntan por qué no se debe usar «mestizaje cultural» y dan varias razones (simplificación extrema operada por la gran división colonial, jerarquizante y excluyente, entre «indios» y «españoles», supuestamente reconciliados en el «mestizaje», que pasa por alto la riqueza de la multiplicidad cultural; trata a las culturas como si fueran entidades corpóreas con capacidad de mezclarse de modo similar a los seres orgánicos; es una metáfora que lejos de ayudar a entender la realidad, más bien conduce a confundirla. «Por todo ello, nos parece más provechoso dejar de lado ese término y centrarnos en lo que realmente importa.» Otros autores han resaltado su carácter mistificador de los conflictos culturales y de las historias de dominación y de explotación; su función instrumental para procesos estato-nacionales de homogeneización; compensación simbólica, pero no real, de los mestizos en los procesos de desarrollo y política progresistas. Así, pues, asimilación, aculturación, subordinación y renuncia, serían formas de expresar lo que el mestizaje ha supuestos históricamente como estrategia de dominación.

3 Véase D. Velasco. «Mestizaje», en J. Conill (coord.). Glosario para una sociedad intercultural. (2002). Bancaja. Valencia, pp. 243-252. 
que algunos estudiosos llaman ya el «trauma poscolonial.»4 Así inicia la periodista su reportaje.

Entre las diferentes razones que están detrás de esta irracional y peligrosa práctica, hay, en mi opinión, una que es fundamental, y es la que Taguieff llama «la obsesión del mestizaje» que se sigue manifestando en el peso que sigue teniendo el color de la piel a la hora de conferir la identidad y de afirmar la diferencia, y que es una expresión clara de la persistencia de un imaginario racista. Es obvio que no es el color de la piel, en sí mismo, la razón objetiva de tal comportamiento. Defensores de la negritud, que están orgullosos de su piel de ébano, o devotas musulmanas, para quienes cambiar el color de la piel equivaldría a poner en duda la creación de Alá, y que son, también, detractores de dichas prácticas, como concluye diciendo la autora del reportaje, son prueba evidente de ello. Es la forma en que los sujetos humanos de diferentes colores participan en el proceso de construcción social de la realidad y la forma en la que se autocomprenden a sí mismos en dicho proceso, la que permite entender la instrumentalización del color de la piel con el objeto de pretender legitimar posiciones de dominación o servidumbre, de discriminación y exclusión sociales, de afirmación reduccionista y polémica de la propia identidad. Son siempre razones ideológicas, entendiendo éstas en su sentido más plurirregional (culturales, socioeconómicas, religiosas, políticas), las que subyacen a tal obsesión y en ellas hay que buscar tanto la etiología como la terapia de comportamientos indignos de llamarse humanos.

Es paradójico que, en pleno siglo XXI, cuando estamos cargados de razones de todo tipo para afirmar la igualdad de todos los seres humanos, sin distinción de raza o color, y con ordenamientos jurídicos que penalizan el racismo, persista de forma tan llamativa esta «obsesión por el mestizaje» que parece devolvernos a situaciones ya superadas, como las señaladas por la figura hegeliana de la dominación y de la servidumbre. Parece oportuno recordar lo que Tocqueville decía en $L a$ Democracia en América, refiriéndose al problema racial en los Estados Unidos de su época y que, como tantas otras cosas que dijo, gozan de una extraordinaria vigencia. «Lo que resultaba más difícil entre los antiguos era modificar la ley. Entre los modernos, es cambiar las costumbres y, para nosotros, la dificultad real comienza donde la Antigüedad la veía terminar. Esto viene de que entre los modernos, el hecho inmaterial y fugitivo de la esclavitud se combinó de la manera más funesta con el hecho material y permanente de la diferencia de raza. El recuerdo de la esclavitud deshonró a la raza, y la raza perpetúa el recuerdo de

4 A. Carbajosa. El País, 28/III/2004. 
la esclavitud (...). Los modernos, después de haber abolido la esclavitud, tienen, pues, que destruir tres prejuicios mucho más intangibles y más tenaces que ella: el prejuicio del amo, el prejuicio de la raza y, en fin, el prejuicio del blanco. Nos es muy difícil a quienes hemos tenido la dicha de nacer en medio de hombres que la naturaleza había hecho nuestros semejantes y la ley nuestros iguales; nos es muy difícil, digo, comprender qué espacio infranqueable separa al negro de Africa del europeo (...) El prejuicio de raza me parece más fuerte en los estados que han abolido la esclavitud que en aquellos donde la esclavitud subsiste aún, y en ninguna parte se muestra más intolerable que en los Estados donde la esclavitud ha sido siempre desconocida.» ${ }^{5}$

Parece como si, hoy, tras una larga tradición de razón crítica, cobrara cada vez más fuerza la tesis de que vivimos bajo la hegemonía de la Razón Cínica, entendiendo por tal, la que se carga de razones para defenderse de la razón y para negar la realidad de una humanidad mestiza.

Creo que aprender a vivir mestizamente es una forma de ejercer la crítica de dicha razón cínica y de realizar una praxis transformadora, que nos lleven a construir relaciones humanas más igualitarias y respetuosas de nuestras diferencias.

\section{Aprender a («imaginar») pensar la realidad mestizamente}

Los seres humanos no podemos vivir en un mundo caótico, anómico y sin sentido, por lo que permanentemente estamos generando el orden, las definiciones y el sentido que necesitamos para entendernos y entender todo lo que nos rodea. Este imperativo cognitivo es el que nos empuja a socializarnos en la comprensión de la realidad y a seguir construyendo la realidad social. Las reglas de juego, los límites, el lenguaje, el parentesco, el intercambio de bienes, las relaciones interpersonales y sociales de todo tipo, las expresiones simbólicas, religiosas y culturales, etc., son la forma en que los seres humanos damos sentido a la realidad. Así, aprendemos a comportarnos y a vivir con un control cognitivo de nuestro territorio cultural que, aunque en algunos casos nos parezca deficiente y no sea el que nos gustaría tener, lo echamos siempre de menos cuando sentimos desorientación o anomía social. El estado hobbesiano de naturaleza se caracteriza, entre otras cosas, porque en él no hay brújula, ni calendario, ni agricultura, ni cultura, ni sociedad, ya que no hay nada que medir, cultivar o esperar en una situa-

5 A. DE TocQueville. La Democracia en América, I, 2. ${ }^{a}$ parte, cap. X. (1957), FCE. México, pp. 327 ss. 
ción en la que la vida está condenada por la confusión babélica, por la brutalidad bélica y por la muerte cierta. De ahí, la necesidad imperiosa de «definir» el lenguaje imprescindible para entendernos y para garantizar la seguridad y el orden. Esta será la tarea del Leviatán.

Esta necesidad de ordenar, definir, clasificar y dar sentido a la realidad se ha vivido en no pocos contextos y momentos de la historia humana como una obsesión por «las reglas de pureza», para cuyo cumplimiento estricto se han utilizado todos los recursos posibles, especialmente aquellos que han tenido más capacidad legitimadora, como la religión o las ideologías, siendo siempre instrumentalizados por el poder de turno. El caso más conocido y seguramente estudiado en nuestra tradición judeocristiana es el de las reglas de pureza creadas en el antiguo Israel. ${ }^{6}$ Pero su importancia y trascendencia no se agota en la historia antigua de un pequeño pueblo, sino que, según algunos autores, ha marcado de forma decisiva la posteridad, hasta nuestros días. ${ }^{7}$

No se trata, obviamente, de cuestionar esta constante antropológica que nos lleva a comportarnos como sujetos nómicos, preocupados por la pureza, la verdad y el sentido imprescindibles, sino de resaltar que, cuando esta preocupación tiene una deriva patológica, acabamos queriendo construir un mundo que niega la condición mestiza que nos constituye como seres humanos y que, lejos de garantizar la necesaria construccción de nuestra identidad, se convierte en la negación inevitable de la misma.

La obsesión patológica por la pureza y por sus reglas es la que se refleja en la obsesión identitaria que en nuestros días se ha convertido en una amenaza para quienes creemos que, en sociedades constitutivamente plurales y seculares, como son las nuestras, sólo cabe pensar en la construcción de identidades plurales y mestizas. No es razonable, en un mundo cada vez más multicultural, pretender definir la cultura desde un imaginario nostálgico de un lugar o tiempo inaugurales en los que los grupos humanos vivieron separados e incontaminados.

No quisiera transmitir la impresión de que trivializo el alcance que en la historia humana, particularmente en nuestros días, ha tenido y seguirá teniendo el conflicto sociocultural, originado por la creciente multiculturalidad, así como por las relaciones siempre asimétricas e in-

6 Véase el número monográfico de la revista Reseña Bíblica dedicado a la «Biblia: Memoria y mestizaje», en el que desde diferentes perspectivas se analiza el tema que aquí nos ocupa y se hacen aportaciones de gran interés. (N. 40. 2003. Verbo Divino. Estella.)

7 Barrington Moore, Jr. Pureza moral y persecución en la historia (2001). Paidós. Barcelona. 
justas que en ella se tejen y que de ella se derivan. No se trata, como dice Sartori, de alimentar el «vacío de comprensión» en el que nos precipitamos, cada vez más, cuando no reflexionamos suficientemente sobre la integración de lo diferente y extraño, conscientes de las enormes dificultades en que nos encontramos. ${ }^{8}$ No pretendo, pues, obviar en ningún caso la espinosa cuestión de los límites del pluralismo o la dificultad que los seres humanos tenemos para poner en práctica «la figura del reconocimiento», sobre todo, si queremos llenarla del contenido de «razón compasiva», al que nos invita la misma tradición judeocristiana a la que me he referido. Basta con abrir los ojos y ver cómo nos comportamos, incluso cuando parecemos reaccionar de la forma más solidaria y generosa con nuestros semejantes, para verificar las profundas raíces insolidarias de nuestros particularismos. ${ }^{9}$ No podemos olvidar que la otra figura hegeliana de «la dominación y la servidumbre» es también constitutiva de toda relación humana, y que se alimenta de y, a la vez, alimenta, lógicas de apropiación y de objetivación de los otros, que, cuanto más otros son, más hostiles nos parecen. Pero me parece una posición irracional e injusta diagnosticar la situación de nuestro mundo como «choque de civilizaciones» para, a continuación, promover la terapia de las políticas identitarias, con nefastas consecuencias para la necesaria cohesión social.

Aprender a pensar mestizamente pasa, pues, por deconstruir aquellos imaginarios sociales que nos transmiten la creencia de que ha habido momentos inaugurales en nuestras sociedades, en los que las reglas de pureza eran expresión de una celosa voluntad divina, dogmática-

8 G. SArtori. La Sociedad multiétnica. Pluralismo, multiculturalismo y extranjeros (2001), Taurus, p. 131. Aunque no comparto algunas de las posiciones de Sartori, me parece fundamental plantearnos los retos de la integración de los inmigrantes, particularmente a través de la ciudadanía, sabiendo que entre las diversas categorías de extrañezas hay algunas que son más resistentes a los procesos de mestizaje cultural, como son las religiosas y étnicas, vividas en clave fundamentalista o teocrática. Es obvio que hay que tener en cuenta no sólo el cómo de la integración, sino también el quién se integra y su voluntad de hacer «democráticamente», en conformidad con las reglas de juego del pluralismo liberal. «Hoy, la palabra "pluralismo" está muy de moda, lo que no quiere decir que se entienda bien. Al contrario, la prueba de ese mal entendimiento está en creer que el pluralismo encuentra una continuación y su ampliación en el multiculturalismo, es decir, en una política que promueve las diferencias étnicas y culturales. No. En este libro voy a mantener que esta complementariedad es falsa y que pluralismo y multiculturalismo son concepciones antitéticas que se niegan la una a la otra» (pp. 7-8).

9 Véase la obra de P. Singer. Un solo mundo. La ética de la globalización. (2004). Paidós. Barcelona. De especial interés para lo que digo es el capítulo titulado «Una sola comunidad», pp. 163-208, en el que nos enfrenta ante la precaria convicción con que afirmamos en la práctica la igualdad de todos los seres humanos, especialmente la de aquellos que vamos sintiendo como más lejanos y diferentes. 
mente monoteísta; pasa por deconstruir los imaginarios de los fundamentalismos, particularismos y nacionalismos excluyentes, que se siguen sintiendo herederos de unas tradiciones inamovibles, definitivas, e inmunes a la historicidad humana y a sus cambios.

Para deconstruir estos imaginarios y las políticas identitarias y excluyentes que de ellos se derivan, creo que hay que comenzar por tomar conciencia de lo que significa ser mestizo, culturalmente, es decir, humanamente hablando, para, a continuación, deconstruir los prejuicios de los imaginarios mixtofóbicos y «racistas». Sólo así estaremos en condiciones de asumir las consecuencias que se derivan de nuestra aceptación ilustrada y compasiva de los derechos y libertades que decimos configuran nuestra comprensión de lo humano, individual y socialmente considerado.

\section{III. «Somos mestizos y los mestizos no nos podemos dividir»}

Esta divisa de Shengor deberíamos hacerla nuestra y convertirla en una referencia normativa en el proceso de construcción de sociedades más igualitarias y libres.

«Una cosa es saber que en España había árabes, y otra admitir que ustedes son también árabes. La cuestión es aceptar este pasado como parte de su patrimonio y no como algo magnífico pero ajeno, incluso exótico. Tengo la impresión de que el gran esfuerzo que los españoles han realizado por ser parte de la Unión Europea ha impedido un reconocimiento de este pasado. Porque si ustedes quieren parecerse a los alemanes, no deben tener nada de judíos y nada de árabes.» ${ }^{10}$

Bastaría ver una sola vez la serie televisiva «Memoria de España» para cobrar conciencia de que el mestizaje es una seña de identidad indiscutible de cualquier español. La mezcla demográfica del pueblo vasco, por ejemplo, es algo suficientemente analizado para que pueda ser puesta en cuestión desde nuevas reediciones del imaginario aranista. ${ }^{11}$ Con frecuencia, dice Hastings, tendemos a creer que, porque podemos re-

10 El autor del texto es Serge GRUZINSKI. Recogido por Guillén Galla en un comentario al libro del mencionado autor El pensamiento mestizo. Entre otras cosas, dice que en Sevilla, en el siglo XVI, había un 15\% de negros. (La Vanguardia-Ideas. 23/2/2001).

11 Véase, por ejemplo, José ARANDA. «La mezcla demográfica del pueblo vasco», en Claves de Razón Práctica. N. 87, Noviembre, 1998. Asimismo, José Agustín Goytisolo. «Catalunya, crisol de culturas o elogio del mestizaje humano y cultural». Conferencia pronunciada con motivo de la presentación de la Fundació Gresol Cultural, el 20 de abril de 1994 en Hospitalet. 
montarnos en una genealogía hasta muy atrás (500 años, e incluso 1.500), tenemos un plus de identidad que los demás no tienen. ${ }^{12}$

En la deconstrucción del imaginario hegemónico que aparece en la Biblia, postulando una identidad para el pueblo de Israel que no esté contaminada por los pueblos vecinos, es imprescindible recordar que la identidad fue otra y que Jacob, figura clave en los orígenes del pueblo, es, según la imagen que transmite el Génesis, típicamente mestiza: «su madre es aramea; veinte años de su vida los pasa con un tío arameo; sus dos mujeres son arameas; las dos esclavas con las que tiene hijos, arameas»; José, su hijo menor, se casa con una egipcia, sus nietos son egipcios, etc. ${ }^{13}$ Hago mía la conclusión a la que llega J.L. Sicre cuando dice: «Quienes aceptamos el Génesis como un relato de valor canónico, superior al de cualquier otro escrito judío, preferimos aferrarnos a la antigua imagen del patriarca ambicioso y egoísta, calculador y frío, también sacrificado y sufriente, abierto a todos los pueblos y culturas, en cuya historia resplandece con luz propia la acción de Dios. Y preferimos la imagen de un pueblo de Israel pequeño, débil, pecador, nacido del mestizaje con arameas y egipcias, de las que no tiene nada que avergonzarse, y enormemente querido y bendecido por Dios». ${ }^{14}$

En nuestros días, el proceso de globalización ha potenciado, aún más, los contextos en los que, históricamente, el mestizaje se ha realizado de forma más decisiva, como han sido las fronteras y las ciudades. ${ }^{15}$ B. De Sousa Santos abunda en su obra La crítica de la razón indolente, en las virtualidades que tiene la frontera y, más en concreto, la vida de frontera como paradigma de una nueva subjetividad emergente y como forma privilegiada de sociabilidad humana. Vivimos en lo que él llama una «sociedad de transición paradigmática», entendida ésta tanto epistemológica como societalmente, ya que ambas dimensiones son, a la vez, autónomas e interdependientes. Afrontar, hoy, de forma progresista, la multiculturalidad exige esforzarse por construir «comunidades ameba» en las que cada uno debemos estar empeñados en la tarea de afirmar un nuevo sentido común emancipador, orientado por una hermenéutica democrática, cosmopolita, multicultural y diatópica, su-

\footnotetext{
12 Hastings, A. La construcción de las nacionalidades. Etnicidad, religión y nacionalismo. (2000). Cambridge University Press. Madrid, pp. 11 ss.

13 Véase J. L. Sicre DíAZ. «Las tradiciones de Jacob. Búsqueda y rechazo de la propia identidad», en Reseña Bíblica, op. cit., pp. 15-31.

14 Ibid., p. 21.

15 Sobre la importancia de las ciudades, como espacios privilegiados de la diversidad y como promotoras de una ciudadanía inclusiva y compleja, se manifiesta la Agenda 21 de la Cultura que se suscribirá estos próximos días en el Forum Universal de la Cultura de Barcelona.
} 
perando así las estrecheces de la ciencia y el derecho hegemónicos vigentes, que son paradigmas de la razón indolente y legitimadores de las «comunidades fortaleza». Para dicho autor, hay tres topoi especialmente aptos para generar la nueva subjetividad individual y colectiva que necesitamos: la frontera, el barroco y el sur. En ellos se resalta, especialmente en los dos primeros, su potencialidad para lograr el deseado mestizaje. ${ }^{16}$ "Lo que importa es captar la fenomenología general de la vida de frontera, la fluidez de sus procesos sociales, la creación constante de mapas mentales (...) La sociabilidad de frontera es, en cierto sentido, la frontera de la sociabilidad. De ahí su gran complejidad y precariedad. Está basada en límites, tanto como en su constante transgresión. En la frontera todos somos, por decirlo de algún modo, migrantes indocumentados o refugiados en busca de asilo (...) Sin embargo, aunque presente algunas semejanzas con el exilio, la frontera no es exilio (...) Al contrario del exilio, en la frontera la "casa común" no es un lugar donde se haya sido expulsado o del cual se viva separado. La vida de frontera es, más bien, la tarea de un constante hacer y deshacer. Por ello, la vida en la frontera obedece al precepto de Adorno ${ }^{17}$, pero además lo complementa con otro, que debe ser seguido de modo igualmente, fiel: la otra parte de la moralidad consiste en que una persona se sienta en casa en aquello que no es su propia casa (...) La complicidad simbólica entre la frontera y la transición paradigmática reside en esta escasez de centros y en la abundancia de márgenes. Vivir en la frontera es vivir en los márgenes sin vivir una vida marginal.» ${ }^{18}$

\section{Deconstruyendo los prejuicios racialistas que imposibilitan la construcción de un imaginario mestizo}

Entre los prejuicios racialistas que más dificultan aprender a vivir mestizamente quiero mencionar, junto a la ya aludida obsesión por las reglas de pureza, un prejuicio que está intrínsecamente vinculado a ella, como es el prejuicio de la «metafísica del uno».

16 B. De Sousa Santos. Crítica de la razón indolente. Contra el desperdicio de la experiencia. (2003). Desclée de Brouwer. Bilbao, pp. 396 ss; el mismo autor plantea la concepción mestiza de los derechos humanos, como única forma de convertirlos en instrumento emancipatorio, en «Hacia una concepción multicultural de los derechos humanos», en F. Gómez (dir.), Manuel Pureza. La protección de los derechos humanos en los albores del siglo XXI (2003). Humanitarian Net. Universidad de Deusto, pp. 95-122.

17 «Cita a Adorno en su Minima Moralia, cuando dice: «constituye una parte de la moralidad el que una persona no se sienta en casa en su propia casa».

18 B. De Sousa Santos. Crítica de la razón indolente, pp. 396-403. 
Ya hemos dicho que la voluntad de ordenar la realidad se ha solido traducir en voluntad de pureza y, para lograr la construcción de un orden definitivo y verdaderamente coherente, que no se vea amenazado por las fuerzas de lo extraño y plural, el imperativo cognitivo se ha esforzado en construir la que aquí llamo «metafísica del uno». ${ }^{19} \mathrm{Y}$, aunque la irreductibilidad de la existencia humana, tan plural y compleja como la vida, a conceptualizaciones metafísicas, religiosas o científicas, ha sido subrayada de forma constante por ideologías y movimientos sociales, casi nunca han gozado del eco esperado, ni mucho menos del favor de los poderes vigentes. La necesidad de querer explicar la realidad desde «la metafísica del uno», desde un único principio supremo, una causa primera, una razón verdadera, un poder originario y omnipotente, etc., y todo ello, desde un imaginario esencialista y dogmático, ha generado una mirada y una praxis reduccionista de lo real que ha obliterado, cuando no borrado del mapa, todo lo que no se ajustaba a dicho imaginario.

La influencia determinante que esta metafísica del uno ha ejercido en ámbitos como el religioso o el político ha impedido que, por ejemplo, quienes han seguido confesando un credo que proclama la realidad trinitaria de Dios, como es el caso de los cristianos, hayan sabido hacerlo desde una actitud pluralista, tolerante, o incluso libertaria. La existencia de cristianos anarquistas y libertarios ha sido sorprendentemente escasa, a lo largo de la historia. A la hora de la verdad, el monoteísmo de carácter monista, y su traducción política en el «modelo del príncipe» absolutista, han servido para construir sociedades humanas en las que el logro de los cuatro objetivos fundamentales que todo grupo social necesita armonizar: salvación, verdad, cohesión y poder, se ha pretendido alcanzar uniformizando la realidad plural desde un único principio constituyente y legitimador. «Une foi, un roi, une loi», será el leit motiv que guiará la construcción de las sociedades bien organizadas. Creo que este imaginario uniformizador no es tanto un rasgo específico del homo religiosus o del homo ideologicus, sino del homo sapiens que acaba instrumentalizando la religión y la ideología para sus objetivos de dominación y exclusión social. ${ }^{20}$

Este imaginario de la metafísica del uno no ha sido exclusivo de etapas premodernas, sino que se ha ido reeditando siempre que el mie-

19 Para abundar en la cuestión de la pureza, véase B-H. LÉvy. La pureza peligrosa (1996). Espasa. Madrid; Z. BAUMAN. La posmodernidad y sus descontentos (2001). Akal. Madrid.

20 Véase D. Velasco. Pensamiento político contemporáneo (2001, 2. ${ }^{a}$ ed.). Universidad de Deusto, pp. 475 ss. 
do a la diversidad, a la disidencia, a la sombra, al cuerpo, a la «vielheit», como expresiones de algo caótico y anómico, se ha traducido en un nuevo proyecto de cosmos unitario y ordenado, como en buena medida ha resultado ser el proyecto de una modernidad racionalista, inmanentista y secularista. Así, aunque el origen de la sociedad moderna ha estado marcado por la lucha por afirmar el pluralismo y la secularización, no ha logrado superar la tentación de crear un imaginario metafísico y ha seguido perpetuando una forma de construir la realidad y de legitimarla que ha sido deudora de un racionalismo reduccionista (las críticas nietzscheanas y de la fenomenología lo han subrayado bien), de un etnocentrismo imperialista y excluyente (la tesis de Dussel de la «inclusión excluyente» me parece acertada), de una configuración estatonacional de la sociedad, que, a pesar de haberse planteado desde el concepto democrático de la ciudadanía, ha estado hipotecada a lógicas no democráticas como la burguesa, la nacionalitaria o la burocrática ${ }^{21}$, de un globalismo, en fin, que no sin razón se ha merecido el apelativo de «pensamiento único».

E. Poulat ha recordado recientemente, en una magnífica obra escrita en plena polémica sobre la laicidad republicana en Francia, que el uso del singular es una trampa que busca encubrir la enorme pluralidad de lo real, en todos sus ámbitos: religioso, político, social, cultural. En todos ellos, el historiador y el sociólogo pueden descubrir con facilidad una sucesión de episteme y de reestructuraciones de lo precedente. El jacobinismo es la fascinación del singular bajo su forma unificada y centralizada. ${ }^{22}$

En el otro extremo de las actitudes que generan prejuicios racialistas están las que E. Garzón Valdés llama «las confusiones acerca de la relevancia moral de la diversidad cultural».

Si es obvio que la tradición liberal ha estado siempre ocupada en construir una sociedad pluralista y secular, expresión del desarraigo de los particularismos premodernos, vistos como privilegios irracionales e injustos, y de un nuevo arraigo en formas libres e igualitarias de pertenencia, no lo es menos que ha tenido dificultades en afrontar de forma adecuada la cuestión de la diversidad cultural, especialmente contemplada desde la perspectiva de los colectivos etnoculturalmente diferentes. Las reflexiones sobre la «metafísica del uno»y sobre el «prejui-

${ }^{21}$ La importancia de esta construcción es decisiva a la hora de plantearnos los procesos de integración social de los «otros» y de aprender a vivir mestizamente. Véase D. VelasCO. Curso de doctorado «Estado y ciudadanía».

${ }^{22}$ Emile Poulat. Notre Laïcité Publique. (2003) Berg International Editeurs. Paris, pp. 353 ss. 
cio de la pureza» han querido abundar en esta cuestión. En las últimas décadas, el liberalismo se ha convertido en blanco de las críticas de quienes parecen tener un modelo alternativo al mismo, como es el caso de los comunitaristas.

E. Garzón Valdés, ${ }^{23}$ con la lucidez que le caracteriza, ha querido puntualizar los peligros que se derivan de una afirmación excesiva de las diferencias en el ámbito de la política, la ética y el derecho, especialmente por la forma confusa en que se utilizan algunos conceptos y en que se legitiman algunos efectos que se quieren hacer derivar de los mismos.

El autor señala cinco confusiones básicas, que, a su vez, generan otras confusiones derivadas:

- la confusión entre tolerancia y relativismo moral,

- la confusión entre diversidad cultural y enriquecimiento moral,

- la confusión entre identidad personal e identidad social,

- la confusión entre unidad cultural y unidad institucional,

- la confusión entre sujetos jurídicos y sujetos morales,

y pasa a analizarlas una por una.

La primera confusión parte de la creencia de que «como las diversas culturas o formas de vida colectiva son inconmensurables, no es posible someterlas a un juicio moral universalmente válido, sino que hay que practicar la virtud de la tolerancia, que estaría basada precisamente en la aceptación del relativismo moral» (p. 10) Sabemos que de la diferencia entre culturas no se puede deducir su absoluta extrañeza, ni la tolerancia puede ser tan extrema que acabe siendo indiscriminada y negándose a sí misma. La cuestión será cómo encontrar las adecuadas razones para ejercer la tolerancia y establecer sus límites, sin caer en la intolerancia insensata. Sabemos que dichas razones pasan por el respeto a los demás y por la búsqueda del bien común, sin ejercer paternalismo alguno y guiándose por el criterio de imparcialidad y universalidad.

La confusión entre la diversidad cultural y enriquecimiento moral nace, según el autor, de que no se tiene en cuenta el carácter a menudo aberrante de muchas prácticas culturales inasumibles desde una defensa mínima de la vida humana y de sus expresiones fundamentales (sacrificios humanos, esclavitudes, etc.). Esta confusión suele ir acompañada de otra que la legitima, como es confundir la moral positiva (la vigente en una sociedad dada) con la moral crítica (la que satisface los criterios

23 E. GARZón VALDÉs. «Cinco confusiones acerca de la relevancia moral de la diversidad cultural». Claves, n. ${ }^{\circ}$ 74. 1997). 
de universalidad e imparcialidad). «La confusión entre diversidad cultural y enriquecimiento moral inmuniza a toda cultura frente a cualquier tipo de crítica moral (tanto externa como interna), ya que ésta sería o bien expresión de arrogancia etnocéntrica o debería ser evitada por razones prudenciales de supervivencia» (p. 13).

Despues de exponer las opiniones de algunos de los representantes de la tesis de que existe una vinculación esencial entre identidad individual e identidad social (Comité ejecutivo de la American Anthropological Association (1947); M. J.Sandel; J. Gray; W. Kymlicka; D. Miller; M. Walzer; K. Lorenz; P. Krebs; Huntington) y de señalar que «no es tarea fácil precisar cuál es el alcance del concepto «comunidad» (como lo muestran posturas como la de Miller, para quien los límites nacionales son los éticamente relevantes, o la de Huntington, para quien lo éticamente relevante es la civilización), pasa a cuestionar la mencionada tesis de que la comunidad es relevante moralmente para el desarrollo de la vida humana individual.

Plantea las siguientes dudas ante las opiniones de los autores antes señalados:

— «No alcanzo a comprender la relación entre comunidad nacional y optimalidad de distribución; y tampoco me parece convincente la vinculación genética entre comunidad (sea esta nacional, tribal o familiar) y Estado de Bienestar.»

— «Tampoco es plausible afirmar sin más que las pequeñas comunidades son siempre la sede de una vida armónica, sin conflictos, en donde el individuo pueda desarrollar más plenamente su libertad.» La reducción de la violencia, comenta, no depende tanto del tamaño como del tipo de creencias compartidas.

— «Es más que dudoso que el postulado herderiano según el cual la pertenencia a un grupo determinado sería una necesidad primaria o elemental. Me cuesta entender, por ejemplo, que la «vida continuada en un mismo suelo» sea una necesidad primaria.»

Refiriéndose a la cuestión de la identidad social, plantea la confusión básica que se da entre desarrollo de la identidad personal y desarrollo de la propia comunidad que trae consigo confusiones derivadas tales como la que se da cuando se confunde la posibilidad de fundamentar un juicio moral con la necesidad de contar con un respaldo comunitario. Dice que es un falso dilema el de ser cosmopolita y entonces se carece de identidad personal o se posee identidad y entonces hay que propiciar una «cultura parroquial». No ve por qué un «ciudadano del mundo» (a lo Kant) haya de tener una personalidad menos desarrollada que los súbditos leales al rey Abd al Aziz. 
Denuncia la «idolatría de los orígenes» que impide una fundamentación universal de los derechos humanos y genera comportamientos discriminantes basados en la defensa de una supuesta autenticidad personal de origen comunitario.

Respecto a la confusión entre unidad cultural y unidad institucional, cita algunos textos jurídicos (el primero de ellos, el Pacto Internacional sobre derechos civiles y políticos, del 66, art. 27) que se refieren a los derechos culturales y a su institucionalización, y plantea algunos problemas:

— «La idea que subyace a esta confusión es la aceptación de una especie de "derecho natural" de las culturas a su perpetuación.» Pero sabemos que estas son formaciones históricas mutables - asociaciones de individuos - cuyas pretensiones deben evaluarse en función de los individuos reales. Los individuos deben poder elegir si permanecer o no en una comunidad cuando no esté en condiciones de ofrecerles las suficientes garantías de una vida digna.

Comentando el mencionado artículo 27 , no cree que de él se desprendan las versiones fuertes de unidad institucional denunciadas, que van mucho más allá de lo prescrito, ya que no sólo imponen deberes negativos de no lesionar las unidades culturales sino también el deber positivo de promoverlas y evitar su desaparición.

Frente a los supuestos derechos colectivos de las comunidades culturales, se plantea la cuestión de si un ente colectivo puede ser portador de derechos morales, como defienden algunos autores (V. van Dyke). Garzón Valdés sostiene que sólo los individuos tienen derechos morales. Defender lo contrario es justificar las más graves violaciones de los derechos de la persona.

«O bien los derechos colectivos no contradicen nunca a los individuales, es decir, que tienen el mismo contenido y por tanto son superfluos, o pueden contradecirlos y nos encontramos nuevamente con el dominico Aimeric (comenta el Manual de Inquisidores), o volvemos a refugiarnos en los derechos individuales.»

«Nadie niega que hay acciones que sólo pueden realizarse a través de la colaboración interindividual. El caso de la autodeterminación o de la secesión son ejemplos al respecto. Pero ello no significa que hay un ente supraempírico que se autodetermina o que se separa de un Estado existente o que sufre si no logra su objetivo. Y si éste no existe no tiene sentido atribuirle derechos o deberes morales... La justificación última de todo derecho jurídico (también los colectivos) es moral. Y precisamente porque lo es tiene que partir siempre de la existencia de intereses individuales legítimos.» 
Como conclusión, su propuesta a las cinco confusiones básicas enunciadas es la siguiente:

«-el rechazo de la tolerancia boba y la práctica de una tolerancia activa que no tenga reparo en rechazar lo intolerable ("coto vedado").

- precisamente porque no todo es tolerable no es lícito moralmente aceptar incondicionalmente toda variedad de vida por el solo hecho de ser diferentes.

—a la vinculación telúrica o étnica incondicionada conviene oponerle la posibilidad de alternativa cosmopolita (posibilidad de poder pasar de una cultura a otra y reconocerse en cada una como ser humano).

- a la confusión entre unidad institucional y unidad étnica cabe responder que si no se quiere caer en patologías jurídicas no hay que asustarse ante la vigencia de un único sistema jurídico dentro de un Estado pluricultural. (Los derechos fundamentales de la persona son el límite moralmente insuperable de toda propuesta de ordenamientos jurídicos alternativos).

- Conviene andar con cuidado y no crear entes supraindividuales portadores de derechos morales colectivos.» (pp. 22-23).

\section{Las identidades polémicas y excluyentes (fundamentalismos \\ y nacionalismos) como legitimación de la desigualdad \\ y de la dominación}

Una mirada reflexiva sobre la forma en que se suelen construir las identidades polémicas y excluyentes descubre, en mi opinión, la siguiente secuencia de la que seguramente algunos de quienes estamos aquí hemos experimentado sus efectos:

Solemos construir nuestra identidad pensándonos desde la narcisista secuencia lógica que supone la autocomprensión de una ciudadanía excluyente, porque excluyente y esencialista es la nacionalidad que la limita, y que al relacionarse con el otro le plantea: 1) deberás ser como nosotros: tendrás que «nacionalizarte», tendrás que dar el perfil exigido por el proyecto nacionalizador; 2) nunca podrás ser como nosotros: siempre hay un label de calidad, que tiene que ver con lo más primordial, como «la tierra y la sangre», y que se utilizará cuando sea preciso reafirmar la particular identidad; 3) aunque no seas como nosotros: aunque no seas de «aquí» ni tengas los apellidos nacionales, te seguimos admitiendo entre los nuestros, incluso, a veces, con un plus afectivo; para concluir, finalmente, cuando el «otro» no responde a las exigencias y expectativas nacionalizadoras, con un: 4) no eres de los nuestros y eres de «los otros», por lo que no sólo no podrás comulgar en nuestros ritos sagrados, sino que tu forma de ser 
«otro» nos molesta y podrás llegar a ser la víctima sacrificada en nuestros altares.

Cuando nuestra forma polémica de afirmar la identidad se hace tan excluyente que llegamos a pensar que los otros son una grave amenaza para nuestro proyecto identitario, pasamos a afirmar esta otra secuencia terrible:

1. Los judíos no podrán vivir entre nosotros como judíos.

2. Los judíos no podrán vivir entre nosotros.

3. Los judíos no podrán vivir.

No creo exagerar si afirmo que el nacionalismo etnocultural, hasta en sus versiones más light, sigue rezumando esencialismo y resistencia a la realidad plural. Por ejemplo, en el nacionalismo vasco democrático, es usual afirmar que España no es una nación, sino un Estado plurinacional. Pero no se añade, a continuación, que la CAPV es también una comunidad plurinacional. La razón de este proceder está en que hay una única nación vasca cuya realidad esencial tiene unas señas de identidad tan irrenunciables que todos los que vivimos en el territorio de la CAPV debemos asumir como propias. Nacionalizarse mediante la asunción de estas señas de identidad es el umbral mínimo de un llamado vasquismo que se impone para todos, porque, se dice, es lo «prepolítico» que nos constituye a todos. ${ }^{24}$

\section{Educarnos en la convivencia mestiza}

\section{Topopoligámicos y con memoria compasiva}

En estos tiempos de globalización tenemos la oportunidad y el reto de pensar nuestro mundo trascendiendo la concepción espacial y temporal que han convertido en miope y reduccionista nuestra forma de entender la identidad de lo humano. Reyes Mate lo ha dicho magníficamente en un artículo titulado «Memoria y Globalización», en el que, además de recordar todo esto, ha subrayado lo que la Ilustración occidental ha silenciado: que no sólo debemos imaginar a los otros y hacerles justicia (a lo Rawls o a lo Habermas), sino que debemos aprender a entender que su diferencia, la de cada ser humano, nace, sobre todo, de una historia escrita desde la exclusión y la injusticia. Debemos ejercitar la memoria passionis que nos obliga a responsabilizarnos de quienes son víctimas de una situación en la que nosotros hemos sido beneficiarios netos.

24 Véase X. AYERDI. «Claves para evitar una fractura social y regenerar la convivencia», en Palabras de Paz/Bake hitzak. N.53, año XXI. Marzo 2004, pp. 53 ss. 
Desde esta nueva mentalidad, no etnicista y dinamizadora de una ciudadanía inclusiva, es posible adoptar las imprescindibles medidas de una integración razonable de la inmigración, en los diversos aspectos que hemos analizado.

La aventura humana del desarraigo, para arraigar de nuevo, tiene que realizarse adecuadamente, tanto en del «desarraigo necesario», el que nos desarraiga de las pertenencias premodernas y desigualitarias, como en el «desarraigo deseado», el poder salir y entrar en formas de asociaciones diferentes. Si no se posibilitan estos desarraigos, se dará una carencia democrática y una indebida asunción del liberalismo democrático. En este contexto me parece interesante la polémica provocada por el Rawls de Política liberal y de El Derecho de Gentes.

\section{Iguales porque diferentes. El valor de la diferencia asociado a poder ejercer el derecho a la indiferencia}

Si algún objetivo tiene el aprender a vivir mestizamente, no es el resaltar la variopinta policromía que adorna a nuestras sociedades, sino resaltar la necesidad de aprender a ver más allá de la multitud de las diferencias de color, de sexo, de clase, etc., a seres humanos iguales en dignidad. En este sentido, me parece sugerente la afirmación de que el mejor hábito para asistir a una convención moderna es el velo de la ignorancia que deja las vestimentas étnicas en casa.

Me remito, de nuevo, a la polémica que ha desatado el Rawls de Política Liberal, al enmendar su propia teoría de la justicia y al espesar el velo de la Ignorancia. Y todos sabemos la polémica desatada en Francia a propósito de ese otro velo, el de las escolares musulmanas, también cargado de polisemia.

Más allá de las muchas disquisiciones que podríamos hacer al respecto, quiero hacer dos observaciones.

En primer lugar, creo que es absolutamente pertinente mantener el velo de la ignorancia, porque sigue siendo imprescindible para poder ejercer nuestro juicio con imparcialidad y equidad, sin tener en cuenta el color del enjuiciado.

En segundo lugar, creo que no se debe levantar el velo impúdicamente, como diría Nietzsche, porque no siempre el levantamiento del velo ha sido ni sigue siendo una tarea de desenmascaramiento necesario.

Con frecuencia, la única forma de poder conjurar el racismo vinculado a las secuencias anteriormente analizadas pasa por mantener un velo de ignorancia con el que no pueden contar los «otros» cuando son prisioneros de su identidad, de su «verdad cultural», por estar siempre obligados a tener que dar razón de su «diferencia», por tener que explicar que 
si no es como nosotros, no está contra nosotros, por lo que podemos estar tranquilos. Cualquier ser humano tiene derecho a poder ser un ser humano más de la calle, un anónimo ciudadano que puede vivir su «vida privada», sus costumbres y creencias, sin verse expuesto a la mirada pública e impúdica, aunque esta mirada sea benévola, como la de las ONGD o la «antropológica». El derecho a la indiferencia es, en este sentido, un derecho prioritario para quien busca ser un ser humano normal en un espacio social y público que lo discrimina y excluye por ser diferente.

No podemos olvidar que, con mucha frecuencia, detrás de los postulados multiculturalistas están exliberales que buscan secularizarse en su pasado de etnocentrismo e imperialismo liberal, pero lo hacen reproduciendo una sociedad fragmentada por los particularismos nacidos de la diversidad cultural. Roy C. Macridis y Mark L. Hulliung ponen entre otros ejemplos de lo dicho el de la Orquesta Sinfónica de Boston, que hasta 1994 aplicaba el velo de la ignorancia para ocultar la identidad. Los jueces de los músicos que se examinaban para lograr una plaza se sentaban detrás de un velo que ocultaba la identidad étnica y el género de los candidatos. En 1994 se contrató a un «asesor sobre diversidad» que «inmediatamente sumergió a la sinfónica en el discordante mundo de la política multicultural... Los oponentes de la propuesta multicultural acusaron, lo que no sorprendió a nadie, a los «asesores sobre diversidad» de crear la tensión racial y étnica que deberían haber aliviado y para lo cual se les había contratado». ${ }^{25}$

Concluyo suscribiendo el imperativo cultural que, según afirma B. De Sousa Santos, «tiene que ser aceptado por todos los participantes en el diálogo si queremos que la hermenéutica diatópica tenga éxito: las personas tienen derecho a ser iguales cuando la diferencia les haga inferiores, pero también tienen derecho a ser diferentes cuando la igualdad ponga en peligro su identidad». ${ }^{26}$

\section{Construyendo sociedades abiertas y superando las solidaridades excluyentes}

Sociedades abiertas son aquellas en las que a nadie se le imponen imperativos de pertenencia que le impiden ser sujeto libre (I. Berlin). Esto no quiere decir que sean sociedades en las que no hay obligacio-

25 R.C. MACRidis/M.L. Hulliung. Las ideologías políticas contemporáneas (1998) Alianza Editorial, Madrid, p. 348.

26 B. De Sousa Santos. «Hacia una concepción multicultural de los derechos humanos», en op. cit., p. 121. 
nes, sino que las obligaciones imprescindibles que garantizan la libertad no se llegan nunca a transformar en estructuras de dominación.

Para no abusar más de la paciencia del lector, voy a concluir señalando el que, para mí, es, en nuestros días, uno de los rasgos más definitorios de una sociedad abierta a la pluralidad y al mestizaje. Me refiero a la laicidad bien entendida, que no hay que confundir con el laicismo secularista. La polémica desatada en Francia sobre la laicidad, a la que antes nos hemos referido, será una polémica que probablemente se reproducirá también entre nosotros. También la laicidad habría que vivirla mestizamente para que podamos superar los esencialismos cristiano y laico y para que la laicidad no se convierta ella misma en fuente de exclusión. La laicidad, como dice E. Poulat, no es una realidad estática, identificable con la separación de Iglesia y Estado, de Religión y sociedad, sino dinámica. «En lugar de los viejos lazos rotos, surgen nuevas relaciones, nacidas de la vida en un espacio común abierto a todos (...) Nuestra laicidad pública aparece así como el resultado de una sabiduría política y de un sutil equilibrio que no obliga a nadie a sacrificar sus principios, sino que propone a todos un nuevo arte de vivir juntos. Conoció un punto de inflexión histórica cuando comenzó a transformarse de arma de guerra en instrumento de paz en el misterioso crisol de la vida en sociedad (...) La laicidad no es "todo al César, nada a Dios», ni tampoco «todo al hombre, nada a Dios", sino todo a la conciencia y a la libertad de los seres humanos llamados a vivir juntos a pesar de todo lo que les separa, les opone o les divide. El enigma de nuestra laicidad pública es el secreto de todas esas innumerables conciencias que se benefician de ella y la practican. ${ }^{27}$

Actualizar las virtualidades de nuestra condición mestiza equivale a aprender a vivir laicamente, ejerciendo libre y solidariamente nuestra forma diferente de ser iguales, construyendo juntos el ideal universalista de una ciudadanía cosmopolita. ${ }^{28}$

27 E. Poulat, op. cit., pp. 13 y 16.

28 Véase D. VelasCo. Etica y políticas para una ciudadanía universal (2002). IDTP/Descléé de Brouwer. Bilbao. 